\title{
Tagungsplanung des AEI für das Jahr 2013
}

Thema: Grenzen der Integration: Europas strategische Ansätze für die Nachbarregionen

Datum: 23.-25. Januar 2013

Tagungsort: Europäische Akademie Berlin

Partner: $\quad$ Europäische Akademie Berlin

Betreuung: $\quad$ Prof. Dr. Eckart D. Stratenschulte, Ilona Rathert

Thema: $\quad$ Police cooperation in the EU under the Treaty of Lisbon - legal and practical opportunities and limitations

Datum:

Tagungsort: 21./22. Februar 2013

Partner:

Hochschule für Wirtschaft und Recht, Berlin

Betreuung:

Thema:

Hochschule für Wirtschaft und Recht, Berlin

Prof. Dr. Hartmut Aden

Datum:

Limits of Democratic Participation: National Parliaments and Multilevel Democracy in Europe

Tagungsort: Europäische Akademie Berlin

Partner: $\quad$ Universität zu Köln

Betreuung: Prof. Dr. Wolfgang Wessels, Dr. Katjana Gattermann, Claudia Hefftler, Oliver Höing

Thema: $\quad$ Limits of EU Powers: The EU between "an ever closer union" and NonTransferable Core State Functions of Member States

Datum: 22./23. März 2013

Tagungsort: Europäische Akademie Otzenhausen

Partner: $\quad$ Universität des Saarlandes

Betreuung: $\quad$ Prof. Dr. Thomas Giegerich

Thema:

Persönliche Grenzen: Die Rolle individueller Politikermerkmale für ökonomische Performance in Europa

Datum: $\quad$ 11./12. April 2013

Tagungsort: Zentrum für Europäische Wirtschaftsforschung, Mannheim

Partner: $\quad$ Zentrum für Europäische Wirtschaftsforschung und Universität Freiburg

Betreuung: $\quad$ Dr. Friedrich Heinemann, Marc-Daniel Moessinger, Prof. Dr. Lars P. Feld

Thema: $\quad$ Neue USA-Politik der EU?

Datum: 21.-23. Oktober 2013

Tagungsort: Europäische Akademie Berlin

Partner: $\quad$ Europäische Akademie Berlin

Betreuung: $\quad$ Prof. Dr. Eckart D. Stratenschulte, Dr. Andrea Despot

Thema:

AEI-Jahreskolloquium

Datum: $\quad$ 14./15. November 2013

Tagungsort: Heidelberg

Betreuung: $\quad$ Prof. Dr. Ansgar Belke, Dr. Friedrich Heinemann, Prof. Dr. Michèle Knodt, Prof. Dr. Dr. h.c. mult. Peter-Christian Müller-Graff, Prof. Dr. Eckart D. Stratenschulte 